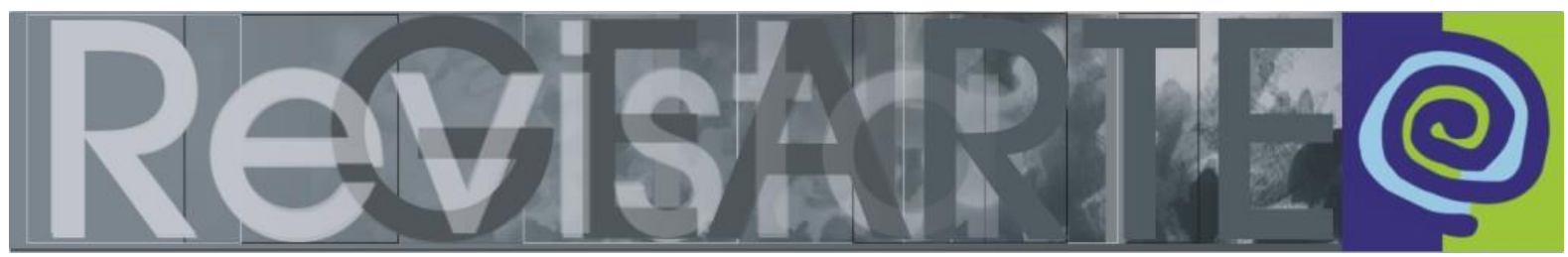

e-ISSN 2357-9854

\title{
Pesquisa(dora) GEARTE: interação e sentido
}

\author{
Marília Forgearini Nunes \\ (Universidade Federal do Rio Grande do Sul — UFRGS, Porto Alegre/RS, Brasil)
}

\begin{abstract}
RESUMO - Pesquisa(dora) GEARTE: interação e sentido - O que é um grupo de pesquisa? Que possibilidades de interação e produção de sentido podem ser identificadas? O presente texto pretende entender como as interações decorrentes da realização da pesquisa e da participação em grupo de pesquisa promovem sentidos a partir dos modos de ser e fazer dos implicados nessa interação sociodiscursiva acadêmica e contagiam cada um dos pesquisadores a partir do diálogo. A base teórica da análise é a semiótica discursiva e alguns conceitos essenciais a respeito da relação entre interação e e produção de sentido são apresentados no início do texto. Na segunda parte, são retomadas experiências vividas em torno da ação de dialogar para traçar percursos interativos de sentido estabelecidos entre pesquisas concluídas antes do meu ingresso no Grupo e pesquisas com construção simultânea à minha. Por fim, apresenta-se reflexão sobre os efeitos de sentido que o convívio dialogado com o GEARTE e seus pesquisadores deixaram no meu fazer pesquisador.
\end{abstract}

PALAVRAS-CHAVE

Grupo de Pesquisa. Regimes de Interação. Diálogo.

ABSTRACT - Research (er) GEARTE: interaction and sense - What is a research group? What possibilities of interaction and production of meaning can be identified? The present text intends to understand how the interactions resulting from the accomplishment of the research and the participation in a research group promote meanings from the ways of being and doing of those involved in this academic sociodiscursive interaction and how the dialogue among the researchers influence this interaction. The theoretical basis of the analysis is the discursive semiotics and some essential concepts regarding the relation between interaction and the production of meaning are presented at the beginning of the text. In the second part, experiences are taken up around the action of dialoguing to draw interactive pathways of meaning established between research completed before I joined the Group and research with simultaneous construction to mine. Finally, there is a reflection on the effects of meaning that the dialogue with GEARTE and its researchers left in my researcher.

\section{KEYWORDS}

Research Group. Interaction Regimes. Dialogue.

Esse texto pretende analisar o convívio com o Grupo de Pesquisa em Arte e Educação, como experiência de sentido a ser compreendida de modo inteligível, mas primordialmente sensível. Nossa atenção estará em experiências vividas no processo de pesquisar vinculada a um Grupo com mais de duas décadas de existência.

Ingressei no GEARTE como pesquisadora em 2010 simultaneamente ao início do Doutorado em Educação junto ao Programa de Pós-graduação em Educação (PPGEDU/UFRGS) sob a orientação da Professora Doutora Analice Dutra Pillar, que há mais de vinte anos coordena o GEARTE. Para explicar o percurso de construção 
de sentidos iniciado nesse momento irei valer-me da teoria sobre a qual debrucei-me [e tenho me debruçado] a compreender para que fosse o referencial teórico da minha tese e hoje seja referencial de base para muitas das minhas reflexões: a semiótica discursiva.

As disciplinas ministradas pela Professora Analice, cursadas junto ao Programa de Educação Continuada, como aluna especial, apresentaram-me à teoria semiótica discursiva proposta por Algirdas Julien Greimas. Apesar da formação em Letras em que os estudos linguísticos são base, a teoria semiótica discursiva não era algo presente para mim, provavelmente fruto da imaturidade da jovem de 17 anos que ingressou no curso de Licenciatura em Letras e que o conclui com apenas 21 anos de idade. Encontrar ou ter o olhar despertado a perceber o que antes estava lá, mas não havia sido notado, foi o que tive oportunidade em relação à semiótica discursiva nas cinco disciplinas cursadas antes de ingressar no curso de doutorado e, posteriormente, ao longo do curso como aluna de doutorado.

Esse texto pretende traçar modos de compreender alguns dos processos de interação e sentido vividos no encontro com o GEARTE e com o estudo da teoria semiótica discursiva. Na primeira parte do texto, em uma escrita mais teórica, apresento conceitos essenciais da semiótica a respeito da relação entre interação e e produção de sentido. Na segunda parte, em uma escrita mais analítica, retomo experiências vividas em torno da ação de dialogar para traçar percursos interativos de sentido estabelecidos entre pesquisas concluídas antes do meu ingresso no Grupo e pesquisas com construção simultânea à minha. Por fim, deixo a sensibilidade exacerbar e finalizarei refletindo sobre os efeitos de sentido que o convívio dialogado com o GEARTE e seus pesquisadores deixaram no meu fazer pesquisador.

\section{Regimes de interação e sentido}

O que apresento aqui são trechos da escrita produzida na pesquisa Leitura mediada do livro de imagem no ensino fundamental: letramento visual, interação e 
sentido (NUNES, 2013) ${ }^{1}$, abordando a teoria que serviu de base para a compreensão da leitura do livro de imagem de literatura infantil cuja mediação foi objeto de investigação. Nesse texto, esses conceitos serão base para explicar a relação entre interação e sentido no convívio em um Grupo de pesquisa com mais de 20 anos e que, portanto, possui um conjunto de pesquisa já concluídas e outras em andamento que afetam o fazer pesquisa de seus componentes.

Dentre as diferentes concepções adotadas para compreender a produção de sentido, tomaremos a da semiótica discursiva, de linha francesa, vinculada a Algirdas Julien Greimas e seus colaboradores. A razão dessa escolha deve-se ao fato de que essa teoria se preocupa em "examinar os procedimentos de organização textual e, ao mesmo tempo, os mecanismos enunciativos de produção e recepção do texto" (BARROS, 2005, p. 12). Assim, o sentido pode ser construído a partir das relações dos elementos que constituem um texto (numa relação interna) e da interação do leitor com esse texto (numa relação externa). Temos, portanto, duas instâncias a partir das quais podemos compreender o processo de significação, o texto, e a prática que envolve a sua leitura (texto-leitor; mediador-texto-leitor).

O processo de significação é entendido pela semiótica como resultado "da reunião [...] de dois planos que toda linguagem possui: o plano da expressão e o plano do conteúdo" (FLOCH, 2001, p. 9). O plano da expressão refere-se às qualidades sensíveis (dimensão eidética, cromática, topológica e matérica) de uma linguagem, utilizadas na sua manifestação discursiva. A manifestação discursiva do plano da expressão nos leva ao plano do conteúdo. O plano do conteúdo é a instância em que o sentido ou a significação são construídos a partir das manifestações sensíveis do plano da expressão, é, portanto, o plano do significado.

O que fica explícito nessa breve definição é que: a semiótica não depende de outra ciência para compreender a produção de sentido em um texto. A semiótica

\footnotetext{
1 A tese completa Leitura mediada do livro de imagem no ensino fundamental : letramento visual, interação e sentido (NUNES, 2013) pode ser acessada no Repositório LUME/UFRGS, no endereço <https://lume.ufrgs.br/handle/10183/87978>.
} 
procura estabelecer o sentido considerando a linguagem que constitui o texto, mas não como sistema de signos, nem mesmo com uma “ 'intenção' explícita de transmitir uma mensagem" (FLOCH, 2001, p. 10). A análise estrutural proposta pela semiótica volta-se para a organização relacional que articula as substâncias sensíveis do texto, constituindo uma forma conotativamente relacionada com as experiências humanas. Dessa forma, o que temos é uma pressuposição recíproca entre expressão e conteúdo, a qual precisa ser considerada no processo de leitura que não ignora o texto, com sua organização, nem o leitor, com seu olhar repleto de experiências.

Essa pressuposição é denominada de semiose e revela a função semiótica presente em todo texto. Com base nisso, ao lermos somos capazes de compreender o que o texto diz (plano do conteúdo) e como diz (plano da expressão), construindo o sentido que nele existe a partir da sua semiose, isto é, da sua forma de expressão relacionada com a sua forma de conteúdo.

Analisar o texto é apenas um caminho para que se compreenda a produção e a apreensão do sentido. Não se pode ignorar, no entanto, que o texto é um objeto deflagrador de interação e, portanto, também essa interação é produtora de sentido. A semiótica considera que o sentido não se dá apenas no nível do objeto, pois este também necessita da interação com o sujeito. É para os modos de interação do sujeito com o mundo - apresentado por meio de objetos ou de outros sujeitos - que alguns estudos da semiótica têm se voltado. Uma semiótica voltada para a experiência do sentido, que não ignora o rigor da ciência do texto de seus primórdios, mas que procura de modo mais filosófico voltar-se a compreender de que modo o mundo nos provoca, se disforica ou euforicamente. Essa alternância, segundo Eric Landowski, não é algo que depende "puramente dos humores subjetivos, modificáveis e inexplicáveis" (LANDOWSKI, 2009, p.14, tradução nossa), mas tem relação direta com os regimes de presença e interação que se inscrevem em nossas relações com o mundo e com o outro.

A compreensão desses modos de interação, no contexto desse trabalho, são relevantes para que se entenda como as interações decorrentes da realização da 
pesquisa e da participação em grupo de pesquisa com existência de mais de duas décadas promovem sentidos a partir dos modos de ser e fazer de todos os implicados nessa interação pertencente ao contexto acadêmico e contagiam a cada um dos pesquisadores de algum modo a partir do diálogo.

Para essa análise, então, buscamos a seguir descrever e explicitar cada um dos regimes de interação e sentido caracterizados por Eric Landowski (2009) ${ }^{2}$ em um movimento de retomada do que foi proposto por Greimas (2002) e de ampliação das reflexões alimentando o devir da teoria.

Segundo Landowski (2001, p. 23), a análise do material de leitura que tenta "resgatar, na sua singularidade e sua especificidade, os efeitos de sentido resultantes da sua própria organização estrutural do objeto", é um caminho que nos ajuda a ver. No entanto, a produção de sentido não é algo a ser considerado somente no nível do texto. A apreensão do sentido envolve também um olhar e a presença desse olhar torna a produção de sentido uma manifestação dinâmica, baseada em interações do sujeito com o objeto ou do sujeito com outro sujeito.

Assim, a semiótica nos permite refletir sobre a produção de sentido tanto nas relações internas estabelecidas na constituição de um texto (objeto concretizado a partir de diferentes expressões verbal, musical, plástica), como também sobre a apreensão do sentido em ato nas interações sociais do cotidiano. Nesse trabalho, nosso olhar estará voltado à interação de uma pesquisadora com o Grupo de pesquisa do qual passa a fazer parte durante o processo de realização da sua investigação de tese no percurso do doutoramento. Nosso olhar analítico estará nas experiências vividas tanto em Grupo, quanto seus reflexos nas experiências individuais de estudo e leitura que são base em um percurso investigativo.

A produção do sentido com essa perspectiva que associa interação e sentido torna-se ação discursiva. Interessa-nos o fazer dinâmico que permite a produção de

2 O livro referido aqui à época da realização do doutorado não havia ainda sido traduzido e publicado em língua portuguesa, o que só o ocorreu em 2014. 
sentido de modo que se compreenda como interagimos e produzimos sentido com o mundo e tudo que está nele.

Essa mudança no modo de refletir sobre a produção de sentido coloca seu olhar sobre a prática vivida. O livro que principia essa alteração de perspectiva na semiótica é a última obra de Greimas, De l'imperfection, cuja tradução em língua portuguesa, Da imperfeição, foi publicada em 2002. Nessa obra, Greimas coloca em pauta - para os semioticistas e/ou para aqueles que se valem dessa teoria para suas reflexões acerca da produção e apreensão de sentido —, a relevância da cotidianidade das relações vividas como atos de sentido.

A partir dessa nova perspectiva, mais filosófica, "mais livre sobre a experiência do sentido" (LANDOWSKI, 2009, p. 10, tradução nossa), que não se restringe a "uma pura realidade "de papel'”' (LANDOWSKI, 2002, p. 126), vinculada à análise de textos (verbais ou visuais, por exemplo), a semiótica volta-se para o sentido em ato, cuja expressão e discurso se revelam nas interações do dia a dia. Em Da imperfeição, Greimas (2002) analisa os modos de presença dos sujeitos e objetos no mundo numa contraposição entre o contínuo, banal e desprovido de sentido, e o descontínuo, que surpreende e provoca o sentido. É neste cenário que se delineia a variação, a noção de evento estético, "um relâmpago passageiro" que surge na banalidade do cotidiano e, inicialmente, desconcerta o sujeito retirando-o do seu tédio, levando-o ao desconforto da não compreensão.

Observa-se, portanto, que Greimas, configura dois modos de existência: um baseado no contínuo, regular, corriqueiro, sem surpresas, outro deflagrado pelo descontínuo, pelo arrebatador, surpreendente e desconcertante. Segundo Landowski (2009), o que Greimas faz é mostrar-nos dois regimes possíveis de sentido, porém sem distingui-los, compreendendo-os num contínuo da experiência vivida. Baseado nessa noção, Landowski (2009), então, caracteriza quatro regimes de interação que correspondem aos modos de ser e agir dos sujeitos no mundo: regime da programação, regime da manipulação, regime do ajustamento e regime do acidente. 
O regime da programação diz respeito às interações nas quais a regularidade de comportamento é característica principal; estabelece-se um programa de comportamento pré-determinado, determinam-se papéis e funções pré-estabelecidos em uma adaptação unilateral de um sujeito em relação ao outro. Essa modalidade de interação, segundo Landowski (2010), pode ser compreendida a partir da imagem de um círculo, um caminho previsível, sem perturbações ou desvios. Essa previsibilidade auxilia na execução de uma performance de modo que existam papeis determinados aos sujeitos, bem como aos objetos envolvidos na interação.

Para Landowski, esse modo de interação revela segurança, isto é, a possibilidade de poder "calcular com bastante exatidão os riscos que assumo" (LANDOWSKI, 2009, p.21, tradução nossa). Observa-se, portanto, que o regime da programação está muito vinculado a uma relação baseada em papéis definidos que resultam em interações seguras e pré-estabelecidas.

O segundo regime, proposto por Landowski, no entanto, volta-se para discursos e práticas que envolvem muito mais os sujeitos e seus modos de ser e agir. No regime da manipulação a intencionalidade e a interdependência entre os sujeitos são palavras-chave para que a interação se estabeleça; nessa relação o manipulador ou estrategista busca conhecer o outro sujeito com o qual interage para obter a sua reciprocidade ou, como nos diz Landowski (2009) o seu consentimento mais ou menos forçado para que se envolva na interação. Trata-se de uma interação alicerçada em bases desiguais, em que um sujeito utiliza estratégias intencionais para modificar o outro (LANDOWSKI, 2010). Para isso entram em jogo a sedução, que se ativa a partir de razões estratégicas de convencimento, e a subjetividade que aciona a motivação do sujeito visando a modalização que leva ao fazer (o fazer fazer).

A maior incerteza nesse modo de se relacionar, quando comparada ao modo programado, está baseada no querer do sujeito manipulado que precisa estar articulado na intencionalidade da manipulação. Segundo Landowski (2009), todo sujeito é capaz de "querer, crer, saber, poder e, em consequência, também querer que o outro queira (ou não queira), crer que creia, saber que sabe, etc, e fazê-lo saber" 
(LANDOWSKI, 2009, p.26, tradução nossa, grifo do autor). É por possuir essas capacidades e confiar que o outro também as tenha, que a comunicação torna-se possível, bem como a manipulação baseada nos motivos e razões dos sujeitos envolvidos na interação.

Essas capacidades, além de propiciarem a interação, revelam também a individualidade dos sujeitos e, em consequência, as incertezas comportamentais que interferem nas relações. A manipulação, dessa forma, torna-se uma relação delicada de ser estabelecida, pois necessita (re)conhecer o outro com quem se interage, buscando motivá-lo para que suas ações tornem-se intencionais por meio de seu próprio querer e não por resultados de uma mera programação.

A presença do outro na interação torna-se ainda mais forte no terceiro regime. O regime do ajustamento é baseado na co-presença dos atores envolvidos na interação. É um regime que comporta mais riscos do que os outros dois já definidos, porque no plano prático da interação os sujeitos envolvidos não possuem qualquer tipo de hierarquia e os princípios que regulam a interação "emergem pouco a pouco da própria interação, em função do que cada um dos participantes encontra e, mais precisamente [...] em função do que sente na maneira de atuar de seu co-participante" (LANDOWSKI, 2009, p. 46, tradução nossa, grifo do autor). O que se tem é uma relação estabelecida com base na reciprocidade de comportamentos, que permite 0 contágio entre os sujeitos e com a prática em si.

Ao mesmo tempo que esse modo de (inter)agir revela maior risco e incerteza, torna-se, também, mais amplo em termos de produção de sentido. Essa amplitude é decorrente do movimento denotado pela denominação desse regime. Ajustar-se aqui não é considerado, segundo Landowski (2009), por uma perspectiva unilateral, pois isso revelaria programação ou configuração pré-estabelecida. O ajuste, nesse caso, diz respeito a uma acomodação dos comportamentos dos sujeitos envolvidos na interação em ato. Não se trata também de uma acomodação visando a persuasão para que haja submissão, configurando-se pois como manipulação. O ajustamento nesse regime revela o reconhecimento do outro como sujeito de pleno direito, e não 
como algo ou sujeito de comportamento estritamente programado ou facilmente conformado (LANDOWSKI, 2009).

Assim, aproximamo-nos do último regime caracterizado por Landowski e, também da compreensão de que os regimes de sentido não são estanques, nem mesmo se relacionam fixamente no cotidiano da experiência vivida. O risco é inerente ao existir, às práticas da vida. O risco é um desafio que se assume ou que se tem de enfrentar por contingência da ordem natural. Há, no entanto, os riscos que atingem apenas à nós mesmos, e os que afetam a tudo que nos cerca. Contra os quais nada podemos fazer, pois são da ordem natural (terremotos, maremotos, tempestades, ...) e, portanto, pragmáticos. Outros são dependentes do nosso modo de ser e agir em relação ao mundo e aos sujeitos, cujos resultados são percebidos simbolicamente na produção de sentido decorrente das relações fracassadas que se configuram a partir deles.

A noção de aleatoriedade das relações é o pano de fundo do que Landowski denomina o regime do acidente. A imprevisibilidade, característica essencial desse regime, é baseada na ruptura com a regularidade, com a intencionalidade, com uma sensibilidade mal-identificada. Assim, o sentido se constrói baseado no "puro risco" (FECHINE; NETO, 2010, p.8), que perpassa os modos de ser e agir nas interações.

O regime do acidente, portanto, não é somente entendido como uma quarta possibilidade de produção de sentido em uma interação. Trata-se, principalmente, de uma compreensão de que os modos de ser e agir no mundo não são fixos, não obedecem a uma sintaxe rígida que resulta em efeitos de sentido únicos e sempre previsíveis, revelando, talvez, certa significação facilmente identificada.

Esse regime, permite-nos compreender que o puro risco é parte de nosso cotidiano nas relações simbólicas que estabelecemos, principalmente, entre sujeitos cujo querer, dever, poder e saber modalizam os seus modos de ser e de fazer. Nos modos de ser, podemos observar mudanças de estado do sujeito que podem resultar em um comportamento programado baseado na regularidade da ordem modal do 
dever-ser e do poder-ser, ou de um comportamento acidental, que nega qualquer regularidade, demonstrando que nem sempre os sujeitos são previsíveis. Essa mesma falta de previsibilidade revela-se nos modos de agir, que podem ser facilmente manipulados a partir do querer dos sujeitos, ou ainda ajustados aos seus saberes sensíveis, mas também podem ser considerados de maneira equivocada e resultarem numa interação acidentalmente sem sentido naquele contexto sintático.

O risco, portanto, é inerente a cada um dos regimes e, principalmente, ao modo com que entre eles se estabelecem relações de mutabilidade baseadas em suas oposições que, longe de resultarem em total afastamento, os aproximam com o movimento interativo. Dessa forma, reforça-se o fato de que a definição de cada um desses regimes não significa que eles, na prática discursiva, ocorram desarticulados. Segundo Landowski $(2014$, p. 31) "entre esses regimes, a teoria define transições, assim como prevê múltiplas superposições e combinações possíveis", tendo em vista a sua vinculação à dinâmica das práticas discursivas com as quais nos envolvemos. Essa mutabilidade que se dá entre os regimes e no interior de cada um deles, é revelada nas práticas discursivas cotidianas e é a partir delas que o que foi caracterizado por Landowski deixa de ser apenas descrição teórica e se veste de sensibilidade prática, o seu valor existencial e, portanto, sensível.

\section{Diálogos em Grupo de pesquisa: interações e sentidos}

Tendo por base os regimes de sentido descritos anteriormente, a inserção em um Grupo de pesquisa será analisada sob a ótica das interações vividas e dos sentidos produzidos e que contagiaram o percurso dessa pesquisadora. Assumimos o diálogo como ação definidora da interação estabelecida. O diálogo entendido não como "um discurso feito pelo filósofo para si mesmo, que o isole em si mesmo, mas [...] [como] uma conversa, uma discussão, um perguntar e responder entre pessoas unidas pelo interesse comum da busca" (ABBAGNANO, 2007, p.323), um diálogo mediado por pesquisas já concluídas e por pesquisas em andamento. 
O destaque para o fazer dialogado justifica-se, pois a inserção em um grupo de pesquisa pressupõe a troca de ideias, o questionar coletivo bem como a busca por respostas. A presença de afinidades e discordâncias em aspectos teóricos e empíricos das pesquisas torna o fazer da pesquisa inserida em um grupo modalizado pelo sobrevir, aberto ao inesperado que o ato dialógico pressupõe.

A definição de grupo de pesquisa segundo o Conselho Nacional de Desenvolvimento Científico e Tecnológico (CNPq) em seu Diretório dos Grupos de Pesquisa No Brasil possibilita uma análise das interações e sentidos presumidos nessa relação social:

Quadro 1 - 0 que é um grupo de pesquisa?

O grupo de pesquisa é definido como um conjunto de indivíduos organizados hierarquicamente em torno de uma ou, eventualmente, duas lideranças:

- cujo fundamento organizador dessa hierarquia é a experiência, o destaque e a liderança no terreno científico ou tecnológico;

- no qual existe envolvimento profissional e permanente com a atividade de pesquisa;

- cujo trabalho se organiza em torno de linhas comuns de pesquisa que subordinam-se ao grupo (e não ao contrário);

- e que, em algum grau, compartilha instalações e equipamentos.

O conceito de grupo admite aquele composto de apenas um pesquisador e seus estudantes.

Fonte: Diretório dos Grupos de Pesquisa no Brasil

Percebemos na definição que não há delimitação de quantidade de pessoas, porém há uma regularidade demarcada no modo com que o grupo se organiza em torno da ideia de hierarquia de uma ou duas lideranças. A definição dessa hierarquia delimita o valor eufórico, o que pode nos levar a pensar em um organização que se funda em papeis temáticos regulares que visam um fazer advir com resultados substanciais coerentes ao "destaque e liderança no terreno científico e tecnológico" demarcados na caracterização do que se entende por hierarquia nesse contexto.

A caracterização, porém não se encerra na diferenciação, ao contrário, apresenta palavras que estrategicamente revelam a consensualidade em torno de 
modos de ser e fazer: "envolvimento profissional e permanente com a atividade de pesquisa". Assim como, pauta a sensibilidade dos interesses de pesquisa que organizam o grupo a partir das suas decisões para além da questão hierárquica, uma regularidade muito mais simbólica do que uma categorização real de poder ou autoridade que esteja baseada num fazer querer autoritário.

Um grupo de pesquisa, portanto, organiza-se em torno da experiência em pesquisa que deve ser estratégia para contagiar os que a ele (o Grupo) e a ela (a pesquisa) se agregam tendo a intenção de obter resultados. Esses resultados para existirem, porém precisam ser sentidos e vividos por todos, não se reduzem ao seguir o modelo do que coordena o grupo, exigem um fazer que perpassa o querer, o sentir e o sobrevir de todos os envolvidos.

Quem lidera o grupo contagia estrategicamente a partir das suas experiências, do seu percurso pesquisador e profissional, mas não pode interromper a interação no fazer. Esse fazer é modalizado a partir do fato de que a interação em grupo de pesquisa pressupõe uma realização, a pesquisa. O coordenador ou líder do grupo assume, portanto, o papel de agir intencionalmente e estrategicamente, bem como de modo sensível para o fazer fazer, propondo uma relação institucionalmente programada pela academia, o grupo de pesquisa, modalizando o ser também pelo fazer, fazer ser (ou tornar-se) pesquisador.

Landowski (2014, p. 80), mostra em diagrama (Figura 1) os movimentos possíveis entre os regimes de interação, observando que podem ser dois os pontos de partida a deflagrar a interação e, consequentemente o sentido, o acidente, fundado na aleatoriedade das relações e acontecimentos e a programação, assentada na regularidade dos papeis, funções e ações realizadas. Do mesmo modo, no grupo de pesquisa o movimento interativo de sentido pode partir do previsível ou do desconhecido. A incerteza da interação que será estabelecida, porém é menos comum, considerando que o participante de um grupo de pesquisa, independentemente de ser pesquisador iniciante ou não, já (re)conhece o fazer em pesquisa que norteia a organização social e discursiva de um grupo de pesquisadores. 
O ponto de partida regular é mais previsível nessa situação que analisamos. A regularidade, porém não se espera que seja mantida, pois cairíamos no risco da coincidência, da monotonia de sentido, totalmente contrária ao objetivo do fazer em pesquisa. Para que isso não aconteça, a ação dialógica precisa ser assumida, pois a sua intencionalidade, baseada tanto no perguntar quanto no responder, movimentos de investigar e encontrar quase simultâneos ou sobrepostos, será motivadora das interações que se sucederão, acompanhadas de efeitos de sentidos assumidos ou negados nesse processo por cada pesquisador.

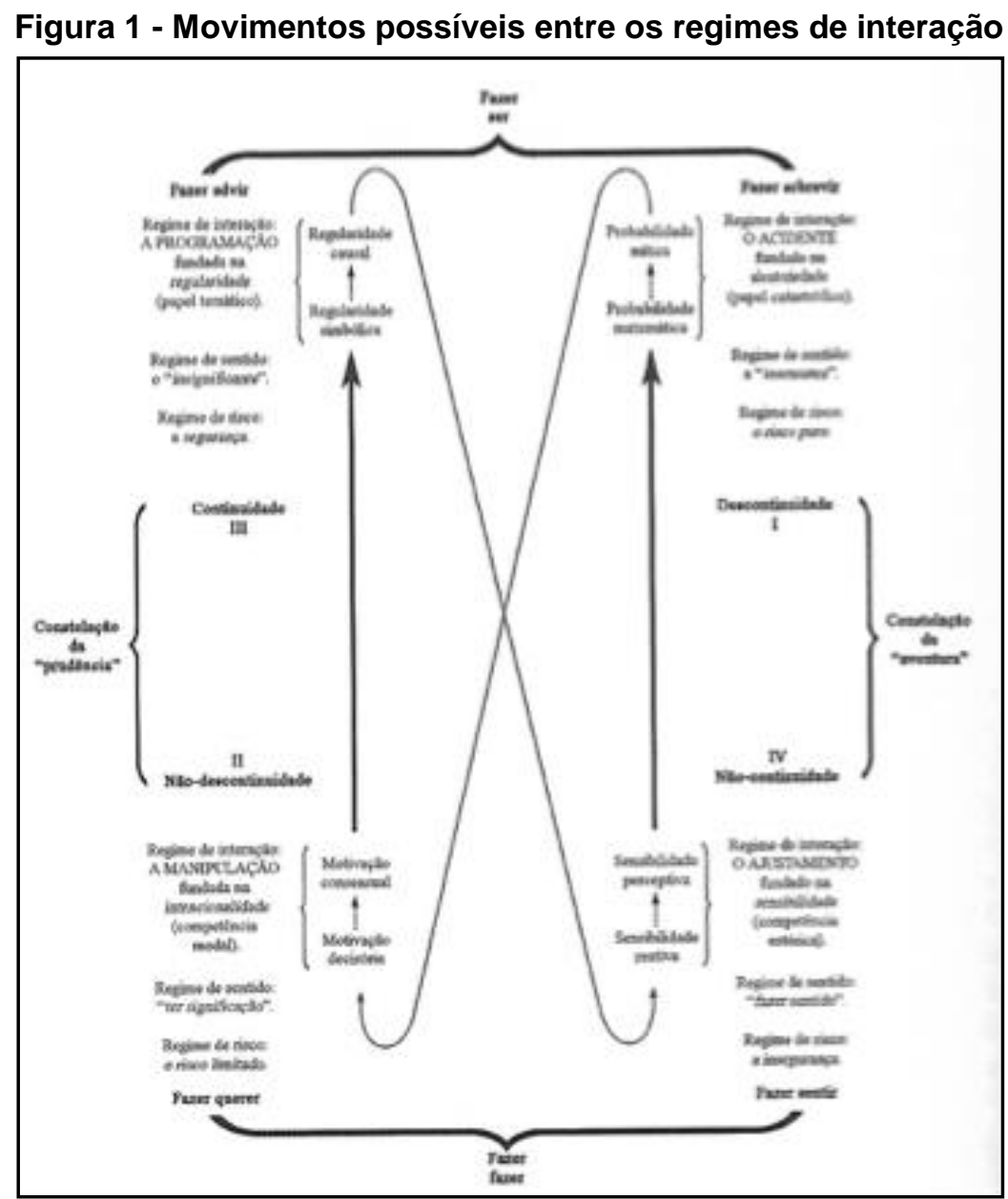

Fonte: LANDOWSKI (2014)

\section{Interações e sentidos no convívio no GEARTE}

Ao ingressar como pesquisadora do GEARTE, o diálogo com pesquisas já realizadas por pesquisadores do grupo, textos já conhecidos provocou o movimento 
interativo de sentido. Buscamos a pesquisa concluída, o percurso programado e regular, para compreendermos o nosso próprio fazer, assumindo comportamentos semelhantes e/ou contrastantes aos nossos na elaboração da nossa pesquisa. Assim, ocorreu com a minha pesquisa que se inseria no GEARTE em 2010 e se identificava com muitas outras, em especial as pesquisas de mestrado e doutorado de Neiva Pannozo $(2001 ; 2007)$.

Na dissertação, Literatura infantil : uma abordagem das qualidades sensíveis e inteligíveis da leitura imagética na escola (PANOZZO, 2001) e na tese Leitura no entrelaçamento de linguagens: literatura infantil, processo educativo e mediação (PANOZZO, 2007), tema, referencial teórico e objeto empírico presentes dialogavam diretamente com as minhas intenções de pesquisa: leitura de imagem, mediação, semiótica discursiva, livro literário infantil. Tais pesquisas possibilitaram o fazer fazer a partir da sensibilidade, do ajustamento ao campo de estudos que me interessava.

Esse movimento sensível de co-participação a partir dos elementos da pesquisa não se encerraram na leitura dessas pesquisa concluídas, ao contrário, impulsionaram o fluxo interativo de sentidos. Acessar as pesquisas de Neiva Pannozo possibilitou estabelecer novos diálogos derivados tanto do contágio, quanto da aleatoriedade trazida pela construção da minha pesquisa, a partir do meu olhar investigativo, traçando o meu percurso na aventura de fazer pesquisa.

As coincidências entre as minhas intenções investigativas e os objetivos traçados nas duas pesquisas finalizadas se ajustaram ao meu fazer investigativo e modalizaram o meu fazer, tornando-o um fazer querer. A leitura das pesquisas foi caminho para identificar brechas investigativas para colocar a minha pesquisa em diálogo com elas. Por exemplo como explico no excerto da tese, estabelecendo relação com a dissertação de Neiva Pannozo que tinha o mesmo objeto empírico pretendido por mim:

Essa dissertação discute a leitura dos textos imagéticos que compõem três livros de imagem da literatura infantil com base em duas perspectivas: a educacional e a semiótica visual. A intenção é apresentar a imagem como objeto de significação de modo que deva ser tratada como "texto lisível" [grifo da autora no resumo]. A 
partir disso, indica a necessidade de formação dos professores para explorar essa leitura no ambiente escolar. (NUNES, 2013, p. 22).

Por outro lado, o fato de ser parte de um Grupo com pesquisas em andamento, mediou para que a interação não se limitasse à identificação e reconhecimento de sentidos, mas buscasse construir novos sentidos. O diálogo com a pesquisa já realizada e com as pesquisas em andamento foi ação necessária para que a entrega à aventura de produzir sentidos pudesse se colocar em curso.

Uma pesquisa não se faz de súbito, o imprevisto é parte, mas torna o processo talvez mais penoso. Inserido em um Grupo de pesquisa, o fazer investigativo inicia em contexto seguro que oferece ao pesquisador caminhos seguros para poder se entregar a um insegurança necessária, mas a princípio controlada. Esse controle é assentado na sensibilidade, almejando o fazer sentir o sentido.

Pesquisas concluídas nos contagiam para a aventura da pesquisa, pesquisas em andamento nos conduzem à aleatoriedade da construção desses estudos. Ser parte de um grupo de pesquisa é viver o ajustamento sensível e o acidente aleatório. Buscamos respostas às nossas perguntas em um fazer que ao mesmo tempo é acolhido pelo diálogo com os estudos já finalizados, mas é desacomodado pelos estudos em andamento, um movimento aventureiro que necessita tanto do encontro quanto da busca para que o sentido se revele.

O convívio com o GEARTE é abertura para a interação com todos os sentidos que dela podem surgir. Ser parte do GEARTE é experiência inteligível e sensível na constituição conjunta de pesquisadores e pesquisas.

\section{Referências}

ABBAGNANO, Nicola. Dicionário de filosofia. 5.ed. São Paulo: Martins Fontes, 2007.

DEWEY, John. Art as experience. New York: Penguin Books, 2005.

BARROS, Diana Luz Pessoa de. Teoria semiótica do texto. São Paulo: Editora Ática, 2005.

FECHINE, Yvana; NETO, João Pereira Vale. Regimes de interação em práticas comunicativas: experiência de intervenção em um espaço popular em Recife (PE). In: 19ํㅡㄹ Encontro Anual da Associação Nacional dos Programs de Pós-Graduação em Comunicação - COMPÓS. 2010, Rio de 
Janeiro. Anais [...]. Rio de Janeiro: PUC-Rio, 2010, p.1-15. Disponível em: http://compos.com.pucrio.br/media/gt4_yvana_fechine_joao_neto.pdf. Acesso em: 8 jul. 2010.

FLOCH. Jean Marie. Alguns conceitos fundamentais em semiótica geral. Centro de Pesquisas Sociossemióticas, São Paulo, 2001.

GREIMAS, Algirdas Julien. Da imperfeição. São Paulo: Hacker Editores, 2002.

LANDOWSKI, Eric. O olhar comprometido. Revista Galáxia, São Paulo, n.2, p. 19-56, 2001.

LANDOWSKI, Eric. Presenças do outro. São Paulo: Perspectiva, 2002.

LANDOWSKI, Eric. Interacciones arriesgadas. Traducción: Desiderio Blanco. Lima: Fondo Editorial Universidad de Lima, 2009.

LANDOWSKI, Eric. Regimes de interação e sentido na educação. Revista GEARTE, Porto Alegre, 2010 (Comunicação Oral). Disponível em: http://www.ufrgs.br/gearte/eventos.html\#. Acesso em: 30 Jun. 2011.

LANDOWSKI, Eric. Interações arriscadas. Tradução: Luiza Helena O. Da Silva. São Paulo: Estação das Letras e Cores: Centro de Pesquisas Sociossemióticas, 2014.

NUNES, Marília Forgearini. Leitura mediada do livro de imagem no ensino fundamental: letramento visual, interação e sentido. 2013. 254f. Tese (Doutorado em Educação) - Faculdade de Educação, Univsersidade Federal do Rio Grande do Sul, Porto Alegre, 2013.

PANNOZO, Neiva. Literatura infantil: uma abordagem das qualidades sensíveis e inteligíveis da leitura imagética na escola. 2001. 169 f. Dissertação (Mestrado em Educação) - Faculdade de Educação, Universidade Federal do Rio Grande do Sul, Porto Alegre, 2001.

PANNOZO, Neiva. Leitura no entrelaçamento de linguagens: literatura infantil, processo educativo e mediação. 2007. 211 f. Tese (Doutorado em Educação) - Faculdade de Educação, Universidade Federal do Rio Grande do Sul, Porto Alegre, 2007.

\section{Marília Forgearini Nunes}

Professora Adjunta na Universidade Federal do Rio Grande do Sul, atuando no Departamento de Ensino e Currículo, da Faculdade de Educação, na área de Formação pedagógica e linguagem. Professora Permanente no Programa de Pós-graduação em Museologia e Patrimônio(PPGMUSPA). Licenciada em Letras, com habilitação nas línguas portuguesa e inglesa e respectivas literaturas (UFSM,1999), Especialista em Língua Inglesa (PUCRS, 2000), Especialista em Supervisão Escolar (PUCRS-PUCVirtual, 2005), Mestre em Letras (UNISC, PPGL, 2007) e Doutora em Educação (UFRGS, PPGEDU, 2013) com pesquisa financiada pelo CNPq. . Pesquisadora vinculada aos grupos: Grupo de Pesquisa em Educação e Arte - GEARTE (UFRGS/CNPq) e Linguagem e Educação (UCS/CNPq). Editora Associada da Revista GEARTE.

E-mail: mariliaforginunes@gmail.com

Currículo Lattes: http://lattes.cnpq.br/5561310307931640

Recebido em 20 de fevereiro de 2019 Aceito em 24 de março de 2019 